\title{
An Evaluation Model of Academic Record of Electronic and Information Engineering Base on Complex Network Theory
}

\author{
Qingyu Zou ${ }^{1, a}$, Dejun Liu ${ }^{1, b^{*}}$, Huida Duan ${ }^{1, c}$ and Liyun Xing ${ }^{1, d}$ \\ ${ }^{1}$ College of Electrical and Information Engineering of Beihua University, Jilin, China \\ azouqingyu2002@126.com, bdejunliu@126.com, chuida_duan@126.com, \\ dxingliyun116@foxmail.com \\ *The corresponding author
}

Keywords: Academic record evaluation; Network model; Complex network; Model

\begin{abstract}
Student test results are important basis to measure study situation. It is an important method to evaluate the quality of professional personnel training by using students' test scores. This paper construct a curriculum influence value network using the interaction relationship between the courses of electronic information engineering based on complex network theory. Then, the test scores of each subject have been entered into the curriculum influence value network to get the grade evaluation network model of students. Finally, evaluate the quality of professional personnel training of students according to the structural characteristics of the grade evaluation network model. In this paper, we use this model to evaluate the personnel training quality of 10 graduates of electronic information engineering. The results show that the grade evaluation network model can accurately measure the quality of professional personnel training of electronic information engineering students.
\end{abstract}

\section{Introduction}

It is an important content of the university personnel training evaluation system to base on the evaluation of student achievement. A good performance evaluation system can accurately reflect the quality of professional personnel training. The electronic information engineering of colleges has trained a large number of professionals in the field of information industry, which have the basic knowledge of electronic technology, information systems and information characteristics, etc., and can be engaged in various types of electronic equipment and information systems research, design, application and development, etc. At present, the research on the evaluation theory of College Students' examination and evaluation is focused on the quality evaluation of electronic information. The evaluation methods are diversified, the content of evaluation is flexible, and the evaluation standard is not unified. The vast majority of evaluation methods attach great importance to the process of evaluation and the development of the scale. But the key project score of the treatment and evaluation is still very rough. More methods are still in place to the static test ranking, mean, standard deviation, and some even avoid grade evaluation [1-7]. In this paper, we use the influence relationship between each course and the results of each course to establish the network model of student achievement evaluation, according to the structure of the network model to measure the quality of professional personnel training.

\section{Construction of the Complex Network Model of Grade Evaluation of Electronic Information Engineering Students}

Courses of Electronic Information Engineering. Electronic information engineering is a subject used in modern technology such as computer and electronic information control and information processing. The main research are information acquisition and processing, electronic equipment and information systems design, development, application and integration. It set up a total of 70 multi course include the circuit theory, information theory and coding, signal and system, digital signal processing, electromagnetic theory, automatic control principle, etc. We have selected 66 important 
courses which affect the relationship between the students and the students, specific courses as shown in Table 1.

Table 1 Courses of electronic information engineering

\begin{tabular}{|c|c|c|c|c|c|}
\hline No. & Course name & No. & Course name & No. & Course name \\
\hline 1 & $\begin{array}{l}\text { Basic manufacturing } \\
\text { technology practice }\end{array}$ & 23 & Linear Algebra & 45 & $\begin{array}{l}\text { Industrial field bus control } \\
\text { technology }\end{array}$ \\
\hline 2 & $\mathrm{VC}++$ practice & 24 & Probability and Statistics & 46 & $\begin{array}{c}\text { Knowledge extension of signal } \\
\text { and system theory }\end{array}$ \\
\hline 3 & $\begin{array}{c}\text { Electronic technology } \\
\text { practice }\end{array}$ & 25 & $\begin{array}{c}\text { Complex Analysis and Integral } \\
\text { Transformation }\end{array}$ & 47 & Electronic System Design \\
\hline 4 & EDA practice & 26 & Physics of college & 48 & $\begin{array}{l}\text { DSP Technology and } \\
\text { Application }\end{array}$ \\
\hline 5 & Production practice & 27 & Physics of college experiment & 49 & Image Processing Technique \\
\hline 6 & MCU interface practice & 28 & Analog Electronic Technique & 50 & Electromagnetic Field Theory \\
\hline 7 & $\begin{array}{l}\text { ARM information system } \\
\text { practice }\end{array}$ & 29 & Circuit Theory & 51 & Electronic Measurement \\
\hline 8 & DSP practice & 30 & Digital Electronic Technique & 52 & Television technique \\
\hline 9 & Image processing practice & 31 & $\begin{array}{c}\text { Analog Electronic Technique } \\
\text { experiment }\end{array}$ & 53 & $\begin{array}{c}\text { DSP Engineering Case } \\
\text { Analysis }\end{array}$ \\
\hline 10 & $\begin{array}{l}\text { Electronic system } \\
\text { engineering practice }\end{array}$ & 32 & $\begin{array}{c}\text { Digital Electronic Technique } \\
\text { experiment }\end{array}$ & 54 & $\begin{array}{c}\text { Technology of Information and } \\
\text { Coding }\end{array}$ \\
\hline 11 & Graduation practice & 33 & The Professional Introduction & 55 & $\begin{array}{c}\text { Digital Speech Processing } \\
\text { Technique } \\
\end{array}$ \\
\hline 12 & Graduation design & 34 & $\begin{array}{l}\text { Micro-Computer Principle } \\
\text { And Application }\end{array}$ & 56 & $\begin{array}{c}\text { Pattern Identificatio nand } \\
\text { Application }\end{array}$ \\
\hline 13 & Circuit CAD practice & 35 & The Special English & 57 & Multimedia technique \\
\hline 14 & Electronic circuit practice & 36 & Sensors Technology & 58 & Digital communication system \\
\hline 15 & Digital electronic practice & 37 & JaveProgram Designing & 59 & $\begin{array}{c}\text { Optical Fiber Communication } \\
\text { Techniques }\end{array}$ \\
\hline 16 & Electronic $\mathrm{CAD}$ practice & 38 & VC++ Programing & 60 & $\begin{array}{l}\text { The New technology of } \\
\text { electronic information }\end{array}$ \\
\hline 17 & $\begin{array}{c}\text { DSP Comprehensive } \\
\text { Practice }\end{array}$ & 39 & $\begin{array}{l}\text { Single-chip Micro-computer } \\
\text { And Interface Technology }\end{array}$ & 61 & $\begin{array}{c}\text { Application Technology of } \\
\text { Database }\end{array}$ \\
\hline 18 & College Chinese & 40 & Mechanical Drawing and CAD & 62 & Microwave Technique \\
\hline 19 & College Foreign Language & 41 & Signal and System & 63 & Computer Networks \\
\hline 20 & $\begin{array}{l}\text { University Computer } \\
\text { Foundation }\end{array}$ & 42 & $\begin{array}{l}\text { The Principle of } \\
\text { Communication }\end{array}$ & 64 & $\begin{array}{l}\text { Embedded Systems and } \\
\text { Application }\end{array}$ \\
\hline 21 & $\begin{array}{c}\text { Computer programming }(\mathrm{C} \\
\text { language })\end{array}$ & 43 & $\begin{array}{c}\text { High frequency electronics } \\
\text { Technology }\end{array}$ & 65 & $\begin{array}{c}\text { EDA Technology and } \\
\text { Application }\end{array}$ \\
\hline 22 & Advanced Mathematics & 44 & Digital Signal Processing & 66 & Automatic Control Theory \\
\hline
\end{tabular}

Construction of Curriculum Influence Value Network Model. We construct curriculum impact weight network according to the mutual influence relationship of course. The network is a directed weight network. Node in the network is a course in Table 3. The edge of the network is influenced by the relationship, which from the first courses to the application course. The value of edges are the proportion of the knowledge of first course in application course. For example, higher mathematics course is the first course of signal and system course. More than 50\% knowledge of signal and system course are related to the knowledge of higher mathematics. Therefore, there is a point between the two 
nodes of higher mathematics and signal and system, and the weight of edge is 0.5 . The curriculum affecting value network model of electronic information engineering as shown in Fig. 1.

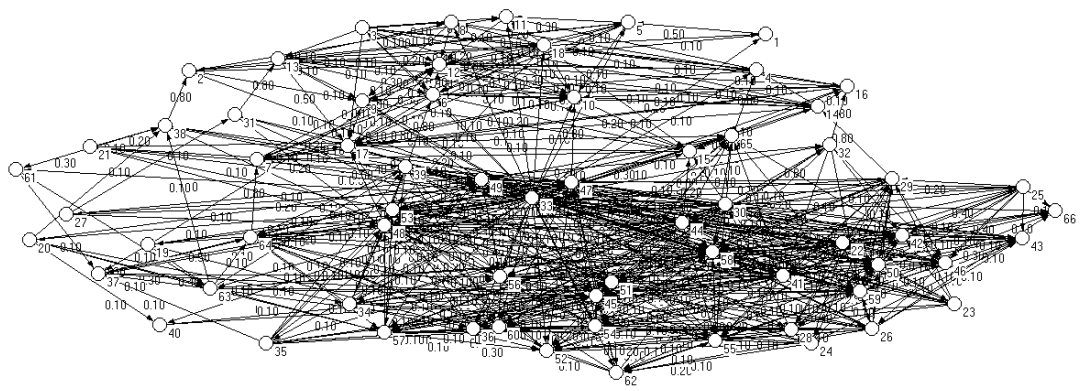

Figure 1. Curriculum influence value network model

Construction of Grade Evaluation Network Model. The curriculum influence value network reflects the influence degree of each course of electronic information engineering. Due to the different grades of different students, we combine the achievement of students and the value network to build the grade evaluation network. The grade evaluation network is divided into two kinds of positive network and reverse network. The weight of the edge of the forward network is equal to the result of the first course and the product of the weight of the edge of the network and the reverse network is equal to 1 minus the weight of the positive network. For example, the grades of all subjects of an electronic information engineering student are shown in Table 2, and then the grade evaluation networks are shown in Fig. 2.

Table 2 High and low settings of predictor variables

\begin{tabular}{|l|c|c|c|c|c|c|c|c|c|c|c|c|c|c|c|c|c|}
\hline Number & 1 & 2 & 3 & 4 & 5 & 6 & 7 & 8 & 9 & 10 & 11 & 12 & 13 & 14 & 15 & 16 & 17 \\
\hline Grades & 70 & 80 & 80 & 70 & 80 & 60 & 72 & 70 & 80 & 80 & 80 & 80 & 80 & 80 & 80 & 70 & 80 \\
\hline Number & 18 & 19 & 20 & 21 & 22 & 23 & 24 & 25 & 26 & 27 & 28 & 29 & 30 & 31 & 32 & 33 & 34 \\
\hline Grades & 90 & 74 & 77 & 83 & 95 & 77 & 72 & 84 & 85 & 90 & 91 & 80 & 74 & 80 & 80 & 70 & 73 \\
\hline Number & 35 & 36 & 37 & 38 & 39 & 40 & 41 & 42 & 43 & 44 & 45 & 46 & 47 & 48 & 49 & 50 & 51 \\
\hline Grades & 80 & 70 & 80 & 70 & 80 & 80 & 60 & 80 & 62 & 87 & 80 & 80 & 60 & 63 & 80 & 70 & 68 \\
\hline Number & 52 & 53 & 54 & 55 & 56 & 57 & 58 & 59 & 60 & 61 & 62 & 63 & 64 & 65 & 66 & & \\
\hline Grades & 80 & 63 & 62 & 80 & 80 & 80 & 80 & 80 & 80 & 80 & 80 & 92 & 80 & 74 & 80 & & \\
\hline
\end{tabular}
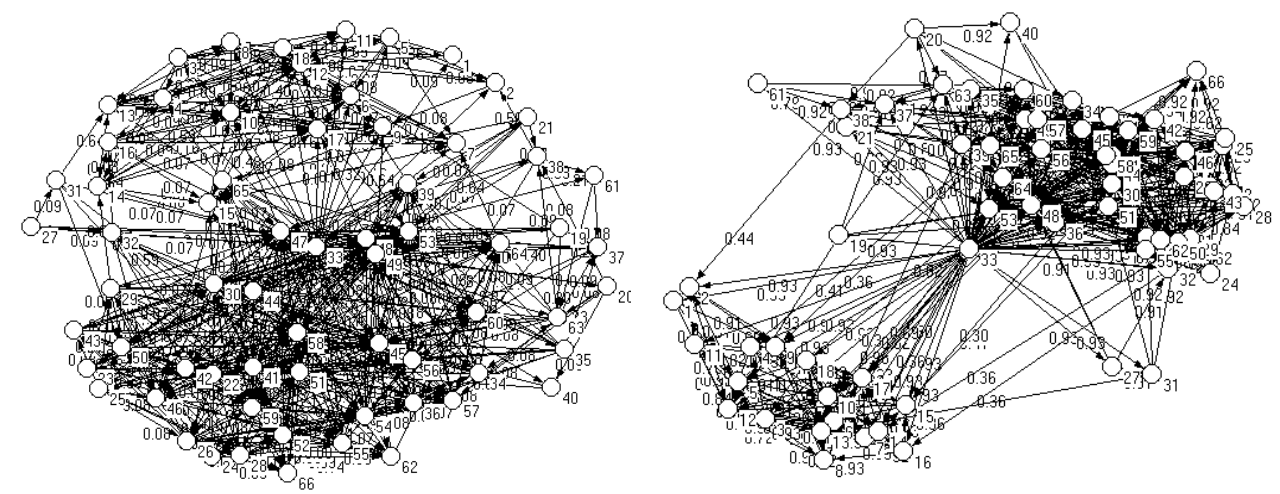

Figure 2. The forward and reverse grade evaluation networks

Degree Centrality. The degree of a vertex in a network is the sum of weight of all the links connected to it [8]. For grade evaluation network, there are an out-degree $k_{\text {out }}$ and an in-degree $k_{\text {in }}$ which are, respectively, the sum of regulating and regulated relations at the node, as shown in Eq. 1. 


$$
k_{i}^{\text {out }}=\sum_{j=1}^{n} A_{i j}, \quad k_{j}^{\text {in }}=\sum_{i=1}^{n} A_{i j}
$$

Where $A$ is the adjacency matrix of network, $A_{i j}$ is an element of matrix $A, A_{i j} \neq 0$ if there is a link from node $i$ to node $j$, the value of $A_{i j}$ is the weight of edge.The total degree $k_{i}$ of a node $n_{i}$ can be computed by the sum of them, i.e., $k_{i}=k_{i}^{\text {in }}+k_{i}^{\text {out }}$.

Closeness Centrality. Closeness centrality measures the mean distance from a vertex to other vertices. A path in a graph is a sequence of nodes and edges, such that a node belongs only to the edges before and after it, and no nodes are repeated [9]. A path length is the sum of edges weight in the path. The smallest sum of edges weight that have to be traversed in a network to get from one node to another is called the distance between the two nodes and a path through the network that achieves that distance is called the shortest path between the nodes. In a teaching evaluation network, there are in-closeness and out-closeness which are, respectively, measures the distance with regulating and regulated nodes. We define $d_{i j}$ is the shortest path length from $i$ to $j$. Then the closeness centrality of node $i$ is the average of the inverse distances, as shown in Eq. 2.

$$
C_{i}^{i n}=\frac{1}{n-1} \sum_{j(\neq i)} \frac{1}{d_{j i}}
$$

Where $C_{i}^{i n}$ is the in-closeness of node $i$.

\section{Result of Application}

We constructed 10 network model of electronic information engineering students using the above method and then calculated average of in-degree, in-closeness and graduation design in-closeness of them [10]. These characteristics of network structure can measure the quality of students training from different angles. The in-degree, in-closeness, graduation design in-closeness, grade point average and learning evaluation value of 10 electronic information engineering students as shown in Table 3 , and the normalized results are shown in Fig. 3.

Table 3 High and low settings of predictor variables

\begin{tabular}{|c|c|c|c|c|c|}
\hline $\begin{array}{c}\text { Student } \\
\text { number }\end{array}$ & In-degree & In-closeness & $\begin{array}{c}\text { Graduation } \\
\text { In-closeness }\end{array}$ & Average & $\begin{array}{c}\text { Evaluation } \\
\text { value }\end{array}$ \\
\hline 1 & 0.876787879 & 0.780832686 & 0.730840119 & 67.24242424 & 9.343 \\
\hline 2 & 0.875742424 & 0.780273195 & 0.738822374 & 67.90909091 & 9.326 \\
\hline 3 & 0.900939394 & 0.78315689 & 0.739940425 & 69.04545455 & 9.277 \\
\hline 4 & 0.89469697 & 0.783253308 & 0.739217757 & 68.98484848 & 9.391 \\
\hline 5 & 0.899727273 & 0.781688579 & 0.74377202 & 70.25757576 & 9.431 \\
\hline 6 & 0.907348485 & 0.783159632 & 0.739861417 & 70.04545455 & 9.41 \\
\hline 7 & 0.934848485 & 0.789257507 & 0.751921833 & 72.68181818 & 9.385 \\
\hline 8 & 1.017924242 & 0.805080969 & 0.7705511 & 77.09090909 & 9.711 \\
\hline 9 & 1.000712121 & 0.798904592 & 0.773998251 & 76.68181818 & 9.664 \\
\hline 10 & 1.122469697 & 0.822506542 & 0.806489599 & 83.59090909 & 9.986 \\
\hline
\end{tabular}

As shown in Fig. 3, the distribution characteristics of in-degree averages are similar to the grade point averages. The distribution characteristics of in-closeness averages, graduation design in-closeness averages are similar to the learning evaluation values. This illustrates using the structural characteristics of the network are more fully and accurately evaluate the quality of electronic information professional students training than the simple average value of the course grades. 


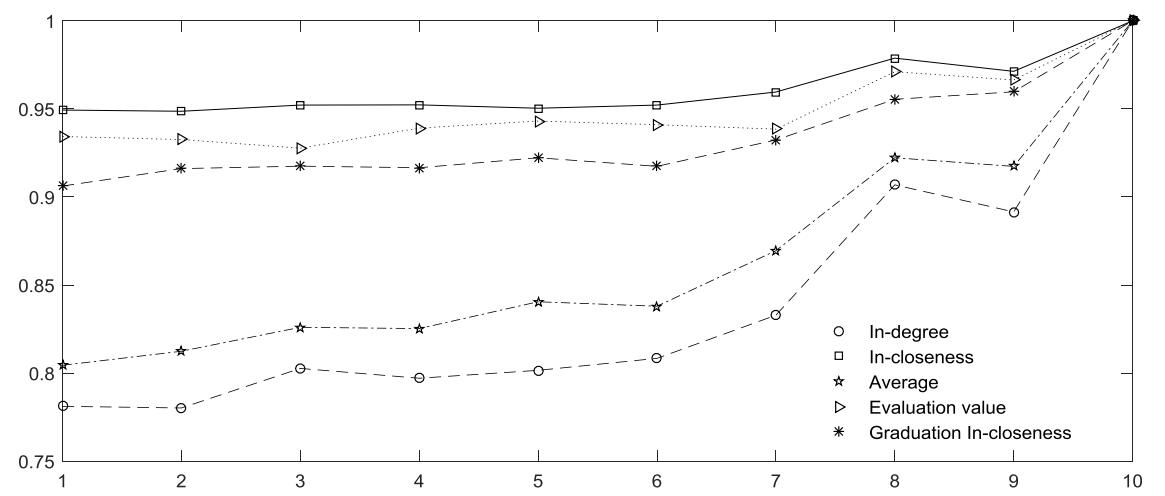

Figure 3. Finite element calculation model of arch dam and bedrock

\section{Conclusion}

The grade evaluation network will be useful to evaluate the quality of electronic information professional students training. Building a grade evaluation network model is a guarantee to promote the students training quality management in higher vocational colleges. Establishing a high quality of students training evaluation network model is directly related to the healthy development of the vocational education. It is the inevitable developing trend of scientific management in the 21 st century education and is inevitable requirement of education facing the modernization, the world and the future.

\section{Acknowledgements}

This work is supported mostly by the Key Education Research Project of Beihua university, partially by the Jilin Province department of education Science and Technology Plan Projects. (Grant NO 2015161, Grant NO. 201658), partially by the Beihua University Dr. Scientific Research Fund (Grant NO. 199500103).

\section{References}

[1] P.B. StarkandR. Freishtat: ScienceOpen Research, Vol.2014 (2014) No.9, p.1.

[2] G.Y. YiandX.D. Wang, Proceedings of the Fourth International Symposium on Education Management and Knowledge Innovation Engineering, (Henan, 2011), Vol. p. 867.

[3] J.B. Zhang, Y.J. ZhangandY.S. Luo, 2nd International Conference on Economics and Social Science (Shenzhen, Jul 29-30, 2014), Vol. 61, p. 243.

[4] J.W. He, M. ZhangandCceoc, Conference on Creative Education (Wuhan, Apr 08-10, 2011), Vol. p. 280.

[5] Y. ShaoandY.Y. Wu, Proceeding of 2012 International Symposium - Educational Research and Educational Technology (Hefei, Apr 07-08, 2012), Vol. p. 413.

[6] Y.Y. WuandY.J. Zhang, Proceeding of 2012 International Symposium - Educational Research and Educational Technology (Hefei, Apr 07-08, 2012), Vol. p. 636.

[7] D.W. LvandD.X. Liu: Research on Evaluation of the Quality of Talent Training of University of Urban Construction, (YanAn, May 21-22, 2010), p. 224.

[8] M.E.J. Newman: Siam Review, Vol.45 (2003) No.2, p.167.

[9] M.E.J.Newmen: Networks: An Introduction (Oxford University Press, New York 2010), p. 139.

[10]L.Y. Cui, S. KumaraandR. Albert: Ieee Circuits and Systems Magazine, Vol.10 (2010) No.3, p. 10 . 